\title{
Short-term outcomes of reconstruction of extensively diseased left anterior descending artery with or without endarterectomy: a propensity score analysis
}

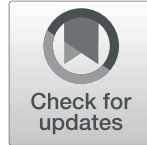

\author{
El-Sayed A. Fayad ${ }^{*}$ iD and Mohamed A. Amr
}

\begin{abstract}
Background: Surgical management of extensively diseased left anterior descending artery (LAD) is challenging. Reconstruction of the LAD with endarterectomy may lead to intimal disruption and affect the outcomes of surgery. We aimed to compare hospital outcomes of surgical reconstruction of extensively diseased LAD with and without endarterectomy.

Results: This retrospective multicenter study included 275 patients who had reconstruction of extensively diseased LAD from 2015 to 2019. We divided patients into two groups: group $1(n=138)$ included patients who had plaque exclusion and patching, and group $2(n=137)$ included patients who had endarterectomy and patching. All patients had primary isolated on-pump coronary artery bypass grafting with the left internal mammary artery (LIMA) grafting to LAD. On-lay LIMA patch was used in 118 patients in group 1 and 132 patients in group 2. A saphenous vein patch was used in 20 patients in group 1 and 5 patients in group 2. Propensity score matching identified 100 matched pairs. The age in group 1 was $56.1 \pm 7.8$ years versus $55.2 \pm 7.1$ in group $2(P=0.34)$. There were 119 (86.2\%) males in group 1 and $113(82.5 \%)$ in group $2(P=0.39)$. After matching, there was no difference in preoperative and operative data. In the matched groups, low cardiac output occurred in 6 (6\%) patients in group 1 and $4(4 \%)$ patients in group $2(P=0.73)$. There was no difference in mechanical ventilation time between groups ( 9 (25th- 75th percentiles: $7.5-14$ ) hours in group 1 vs. $9(7-14)$ hours in groups 2; $P=0.93)$. Length of hospital stay was 7 (6-9) days in group 1 and $7(6-10)$ days in group $2(P=0.57)$. Mortality occurred in one patient in group 1. We did not report early graft occlusion cases in group 1, and one patient had a myocardial infarction in group 2.

Conclusion: The outcomes after reconstructing extensively diseased LAD with endarterectomy or plaque exclusion and patching are satisfactory and comparable in both approaches.
\end{abstract}

Keywords: Endarterectomy, LAD reconstruction, Extensive LAD disease

\section{Background}

Management of a diffusely diseased left anterior descending artery (LAD) remains a surgical challenge. Incomplete revascularization of LAD is associated with increased mortality compared to other coronary arteries $[1,2]$. Endarterectomy is a surgical option to manage a

*Correspondence: sayedfayad_cts@med.suez.edu.eg

Department of Cardiothoracic Surgery, Faculty of Medicine, Suez Canal University, Ismailia 41522, Egypt

\section{Springer Open}

diffusely diseased LAD. Early reports of LAD endarterectomy showed increased postoperative myocardial ischemia and mortality [3]. Endarterectomy leads to intimal disruption and early thrombotic occlusion of the LAD $[4,5]$. Recently, the technique of coronary artery endarterectomy has been evolved, and good results were reported [6].

However, many surgeons are reluctant to perform endarterectomy because of its controversial results. An

(c) The Author(s). 2021 Open Access This article is licensed under a Creative Commons Attribution 4.0 International License, which permits use, sharing, adaptation, distribution and reproduction in any medium or format, as long as you give appropriate credit to the original author(s) and the source, provide a link to the Creative Commons licence, and indicate if changes were made. The images or other third party material in this article are included in the article's Creative Commons licence, unless indicated otherwise in a credit line to the material. If material is not included in the article's Creative Commons licence and your intended use is not permitted by statutory regulation or exceeds the permitted use, you will need to obtain permission directly from the copyright holder. To view a copy of this licence, visit http://creativecommons.org/licenses/by/4.0/. 
alternative option for LAD reconstruction was proposed with plaque exclusion and patching without removing the intimal lining [7]. The left internal mammary artery (LIMA) is the standard conduit for LAD [2, 8], and it can be used for LAD reconstruction as an on-lay graft [9]. Alternatively, a saphenous vein patch combined with LIMA grafting can be used [10].

The superiority of LAD reconstruction with or without endarterectomy has not been established. The results of these surgical methods were reported in a heterogeneous population with a difficult comparison. This study compared the surgical outcomes obtained from coronary artery reconstruction, with or without endarterectomy, for a diffusely diseased LAD.

\section{Methods}

\section{Design and patients}

We performed a multicenter retrospective study that included patients who had reconstruction of an extensively diseased anterior descending artery in combination with conventional coronary artery bypass grafting (CABG) between 2015 and 2019. According to the reconstruction technique, patients were grouped into two groups: group 1 included patients who had plaque exclusion and LAD patch repair without endarterectomy $(n=138)$. Group 2 included patients who had LAD endarterectomy and patch reconstruction $(n=137)$. All patients had isolated primary on-pump CABG and LIMA grafting to the LAD. We excluded patients who had concomitant valve surgery, re-operative and off-pump CABG and those who had LAD graft with a conduit other than LIMA.

The Local Ethical Committee approved the study, and the need for patients' consent was waived.

\section{Data and outcomes}

We retrieved the data required for this study from the electronic and paper records. Preoperative data included patients' demographics, comorbidities, symptoms, and investigations. Operative data included the number of distal anastomoses, cardiopulmonary bypass and ischemic times, and pump parameters. Postoperative data were compared between both groups and included the length of ICU and hospital stay, postoperative complications, and mortality.

Diffuse LAD disease was defined as a long segment or multisegment stenosis of the LAD with at least $1 \mathrm{~mm}$ patent lumen diagnosed in the preoperative angiography. We defined hospital outcomes as those occurring during hospital admission or within 30 days from surgery. Postoperative low cardiac output (LCO) was defined as the need for a mechanical support device or maximum inotropic support $(3 \mu \mathrm{g} / \mathrm{kg} / \mathrm{min}$ for adrenaline and noradrenaline and $20 \mu \mathrm{g} / \mathrm{kg} / \mathrm{min}$ for dopamine and dobutamine). In patients with pulmonary artery catheters, LCO was diagnosed if the cardiac index was less than $2 \mathrm{~L} / \mathrm{min} / \mathrm{m}^{2}$. Myocardial infarction was diagnosed with electrocardiographic changes, including ST changes, Q wave, left bundle branch block, or $\mathrm{R}$ wave progression failure.

\section{Surgical technique}

All patients had CABG through a median sternotomy and aortocaval cannulation. The left internal mammary artery was anastomosed to the left anterior descending artery in all patients unless the mammary artery was short or the anastomosis was very long. In these cases, we used a vein patch first on LAD; then, the LIMA was anastomosed to the vein patch. LIMA was used as a pedicled graft in 132 patients and as a free graft in 6 patients in group 1. Pedicled LIMA was used in 133 patients in group 2 and as a free graft in 4 patients.

Reconstruction of LAD was performed when simple LIMA anastomosis to LAD was not feasible. We performed a mid-LAD incision that extended proximally or distally when needed. The incision was extended to the proximal LAD in one patient in group 1 , and one patient in group 2, and to the distal LAD in one patient in group 2. We patched the LAD with the exclusion of the atherosclerotic plaque from the new lumen. Patients with ulcerated, large soft or fragile plaques, or those with poor distal run-off had endarterectomy.

In patients who had endarterectomy, the cleavage line between the plaque and the LAD was identified, and the atheroma was carefully dissected using a fine spatula. Traction was applied to the atheromatous cylinder proximally to disrupt the proximal end; however, the smooth tapering of the distal cylinder should be achieved (Fig. 1).

LAD reconstruction was performed in both groups using LIMA as an on-lay patch or saphenous vein patch if LIMA is short (Fig. 2). The anastomoses were constructed using 8-0 polypropylene sutures. On-lay LIMA patch was used in 118 patients in group 1 and 132 patients in group 2. Vein patch was used in 20 patients in group 1 and 5 patients in group 2 .

The second conduit used in group 1 was the saphenous vein in 131 patients, the right internal mammary artery (RIMA) in one patient, and the radial artery in one patient. Group 2 had 123 saphenous veins, 1 RIMA, and 3 radial arteries as a second graft.

All patients had intravenous heparin infusion postoperatively for a few days until we achieve the target INR with warfarin (INR 2-3). Warfarin was administered for 3 months; then, the patients continued on low dose aspirin.

\section{Statistical analysis}

Normally distributed continuous data were presented as mean and standard deviation and non-normal data as 

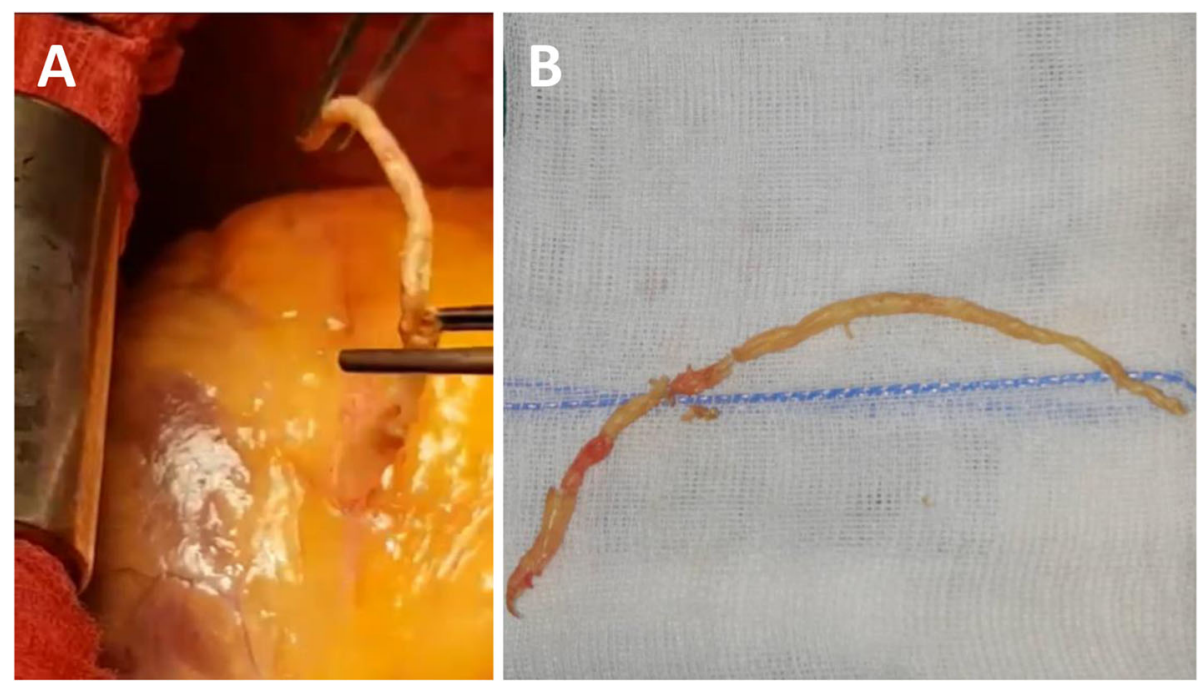

Fig. 1 a Endarterectomy of the left anterior descending artery. b Atheroma extracted from the left anterior descending artery

median and (25th-75th percentiles). Qualitative data were presented as numbers and percentages. $t$ test or Mann-Whitney test was used to compare continuous data and chi-square or Fisher exact test for qualitative data.

Propensity score matching was performed using the nearest neighbor 1:1 match, and we identified 100 pairs of matched patients. Matched pairs were compared using paired $t$ test or Wilcoxon rank-sum test for matched pair if the data were continuous, and matched qualitative data were compared using the Mcnemar test. A $p$ value of less than 0.05 was considered statistically significant. All analyses were performed using STATA 16 (Stata Corp., College Station, TX, USA).

\section{Results}

\section{Preoperative and operative data}

The preoperative characteristics were comparable between both groups apart from the preoperative angina and dyspnea class. In group 1, one patient had preoperative atrial fibrillation, and one required inotropic support. In group 2 , one patient had thrombolysis $24 \mathrm{~h}$ before surgery, and one patient had liver dysfunction (Table 1).

Patients were matched on the preoperative characteristics, in addition to the number of distal anastomoses and urgency of surgery. We found 100 matched pairs with no significant difference in their preoperative and operative data (Tables 1 and 2). There was no difference in transfusion requirement and the support required during weaning from cardiopulmonary bypass between groups.

\section{Postoperative data and outcomes}

Postoperative complications and length of ICU and hospital stay were comparable between both groups.
Mortality occurred in six patients in group 1 (4.4\%) and 5 patients in group $2(n=3.7 \%)$. Blood transfusion was significantly higher in group 2 , and one patient had pancreatitis in group 1 . One patient had a stroke in group 2 $(0.7 \%)$, and two patients had delayed recovery in each group $(P>0.99)$. One patient in group 2 had postoperative MI $(0.7 \%)$.

After matching, there was no significant difference in the outcomes between both groups (Table 3). One patient has a stroke in group 2 . We did not report patients who had early graft occlusion in the matched cohort.

\section{Discussion}

High-risk patients are presented more frequently for coronary artery bypass grafting because of the increased number of percutaneous interventions. A large number of those high-risk patients have a diffusely diseased LAD. Reconstruction of LAD in those patients is essential to achieving complete revascularization and improving survival [11]. Surgical options for the management of those patients include endarterectomy or plaque exclusion and patch reconstruction. Surgical reconstruction of extensively diseased LAD had a better outcome than medical therapy [12]; however, the superiority of one approach over the other is debatable.

We performed a retrospective study on 275 patients to compare the outcomes of reconstructing extensively diseased LAD with or without endarterectomy. We did not find a difference in postoperative outcomes between both techniques, and we did not report early graft occlusion in the matched patients. Fukui and associates compared both approaches in 250 patients, and they reported comparable short and long-term outcomes [7]. In contrary to our results, they reported $6.5 \%$ 


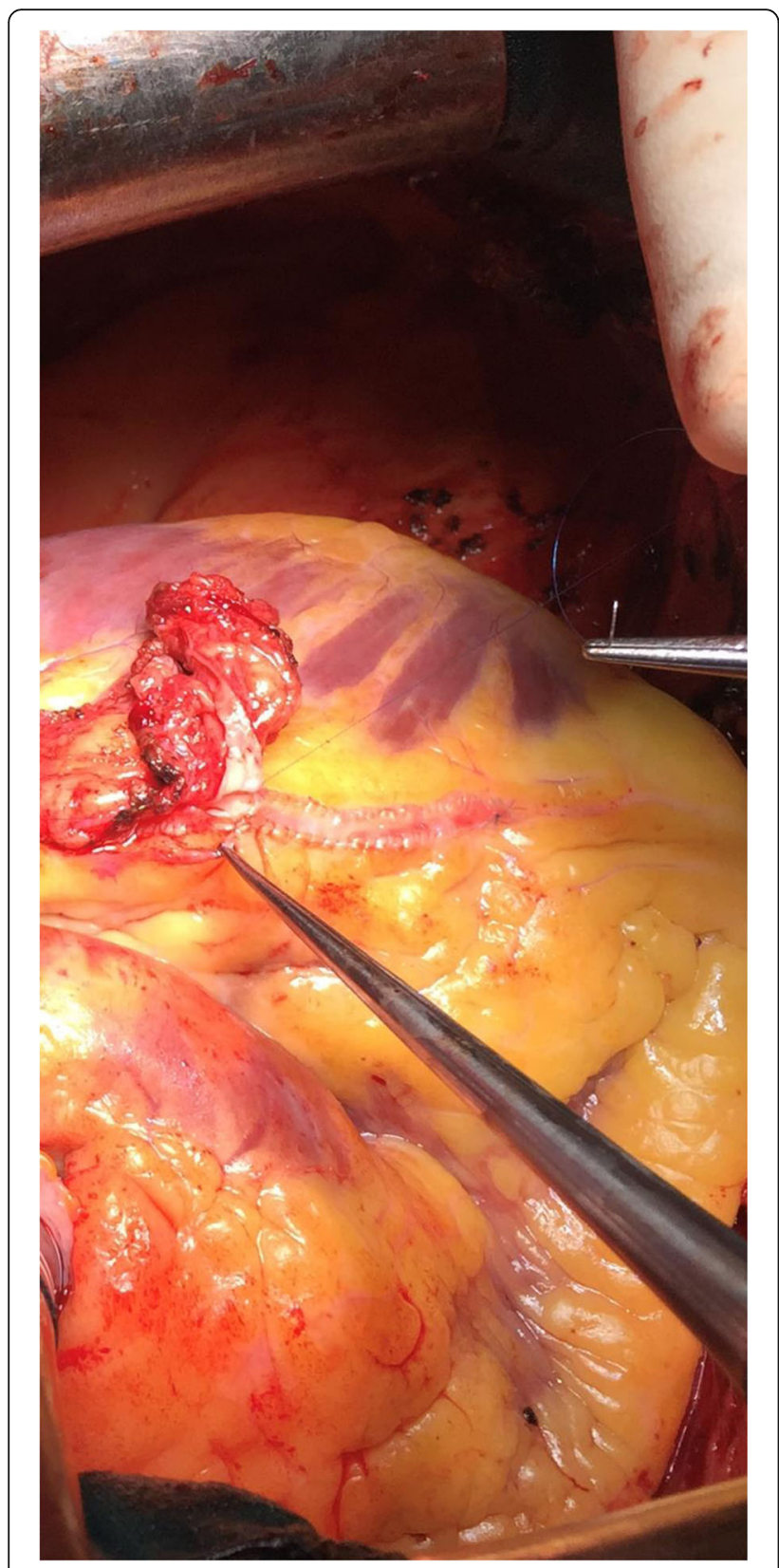

Fig. 2 Left internal mammary artery anastomosis to a long saphenous vein patch on the left anterior descending artery

perioperative myocardial infarction in their cohort. Bitan and colleagues compared both approaches for LAD reconstruction in 166 patients. They found no difference in in-hospital outcomes and long-term survival; however, the freedom from percutaneous interventions was higher in endarterectomy patients [13]. They reported higher ischemic and $\mathrm{CPB}$ times in patients who had endarterectomy, and they attributed this to the concomitant valve surgery and older age of those patients [13]. We did not report differences in bypass times, as we included patients who had isolated and primary CABG, which created more homogenous patients' groups.

Studies comparing both techniques are scarce in the literature; however, several studies reported the outcomes of either strategy separately. Patients who received either treatment option are heterogeneous, which could be attributed to the disease's nature. Endarterectomy is preferred in patients with distal LAD disease and fragile or unstable atheromatous plaque [14].

Both surgical approaches for managing the diffusely diseased LAD could lead to serious postoperative complications [15]. Endarterectomy leads to disruption of the LAD's intimal lining, which could activate the coagulation cascade and lead to early graft thrombosis [5, 16]. Early postoperative aggressive anticoagulation management is essential to prevent such dreaded complications. Our protocol is to start heparin infusion once there is no surgical bleeding until we achieve a satisfactory INR with warfarin. We did not perform postoperative angiographic studies after endarterectomy routinely, and we used ECG criteria to diagnose myocardial infarction. One patient had MI in group 2 and none in the match groups.

Coronary endarterectomy increased postoperative complications and mortality compared to patients who underwent CABG without endarterectomy [17]. However, patients who had endarterectomy had different characteristics compared to patients who did not. A recent meta-analysis showed higher postoperative renal complications, myocardial infarction, and mortality in high-risk patients or those with diffuse LAD disease who had endarterectomy combined with CABG versus isolated CABG. However, when comparing recent reports published after 2000, they found no difference in the short and long-term outcomes between groups [3].

In a study on LAD reconstruction without endarterectomy in 524 patients, Ogus and associates reported 1.9\% mortality, $6.9 \%$ myocardial infarction, and the long-term patency of LIMA-LAD anastomosis was 91.4\% [18]. Some surgeons reported off-pump reconstruction of the LAD [19], and good results were claimed using this approach compared to on-pump reconstruction $[3,13]$.

Several strategies were described to patch the LAD, including saphenous vein patching followed by LIMA grafting or on-lay LIMA patch [20]. Berreta and colleagues compared both techniques of LAD patching in 96 patients, and they reported better hospital and longterm survival with the use of LIMA [10]. Myers and associates compared LAD reconstruction with LIMA versus saphenous vein patch in 244 patients, and they found no difference in long-term survival in both approaches [4]. Because of the superiority of LIMA-LAD on the short- and long-term outcomes after CABG, we used LIMA grafting in all patients, and whenever possible, we used LIMA on-lay graft. 
Table 1 Preoperative data

\begin{tabular}{|c|c|c|c|c|c|c|}
\hline & Group $1(n=138)$ & Group $2(n=137)$ & $P$ & Group $1(n=100)$ & Group $2(n=100)$ & $P$ \\
\hline \multicolumn{7}{|l|}{ Demographics } \\
\hline Age (years) & $56.1 \pm 7.8$ & $55.2 \pm 7.1$ & 0.34 & $56 \pm 7.2$ & $55.3 \pm 7$ & 0.48 \\
\hline Male & $119(86.2 \%)$ & $113(82.5 \%)$ & 0.39 & $85(85 \%)$ & 81 (81\%) & 0.58 \\
\hline BMI $\left(\mathrm{kg} / \mathrm{m}^{2}\right)$ & $30.9(27.8-35.9 \%)$ & $31.1(27.7-33.6)$ & 0.18 & $30.4(28.4-36.4)$ & $31.6(27.7-34.1)$ & 0.53 \\
\hline $\mathrm{BSA}\left(\mathrm{m}^{2}\right)$ & $2.03(1.9-2.1)$ & $1.96(1.89-2.05)$ & 0.07 & $2.03(1.93-2.1)$ & $1.97(1.89-2.01)$ & 0.15 \\
\hline \multicolumn{7}{|l|}{ Comorbidities } \\
\hline DM & 75 (54.4\%) & 65 (47.8\%) & 0.28 & $54(54 \%)$ & $47(47 \%)$ & 0.36 \\
\hline Hypercholesteremia & $61(46.2 \%)$ & $56(41.5 \%)$ & 0.44 & $44(44 \%)$ & $40(40 \%)$ & 0.46 \\
\hline Hypertension & 87 (63\%) & $86(63.2 \%)$ & 0.97 & $63(63 \%)$ & $61(61 \%)$ & 0.87 \\
\hline Hypothyroidism & $3(2.2 \%)$ & $1(0.8 \%)$ & 0.62 & $2(2 \%)$ & 0 & 0.5 \\
\hline Renal impairment & $3(2.2 \%)$ & $1(0.8 \%)$ & 0.62 & 0 & $1(1 \%)$ & $>0.99$ \\
\hline Respiratory disease & $1(0.7 \%)$ & $4(2.96 \%)$ & 0.21 & $1(1 \%)$ & $2(2 \%)$ & $>0.99$ \\
\hline CVD & $2(1.5 \%)$ & $2(1.5 \%)$ & $>0.99$ & $1(1 \%)$ & $2(2 \%)$ & $>0.99$ \\
\hline PVD & $3(2.3 \%)$ & $4(3 \%)$ & $>0.99$ & $3(3 \%)$ & $2(2 \%)$ & $>0.99$ \\
\hline HF (within 1 year) & $3(2.2 \%)$ & $8(6 \%)$ & 0.13 & $3(3 \%)$ & $1(1 \%)$ & 0.63 \\
\hline Previous Ml & & & 0.93 & & & 0.39 \\
\hline 1 attack & 41 (30.2\%) & $39(29.55 \%)$ & & $27(27 \%)$ & 31 (31\%) & \\
\hline 2 or more & $12(8.8 \%)$ & $10(7.6 \%)$ & & $10(10 \%)$ & $5(5 \%)$ & \\
\hline Previous PCl & $11(8 \%)$ & $12(8.8 \%)$ & 0.81 & $9(9 \%)$ & (9\%) & $>0.99$ \\
\hline \multicolumn{7}{|l|}{ Symptoms } \\
\hline Angina class & & & $<0.001$ & & & 0.35 \\
\hline 1 & 0 & $2(1.4 \%)$ & & 0 & 0 & \\
\hline$\|$ & $14(10.4 \%)$ & 35 (25.9\%) & & $14(14 \%)$ & $13(13 \%)$ & \\
\hline III & $122(88.4 \%)$ & $86(63.7 \%)$ & & $85(85 \%)$ & $81(81 \%)$ & \\
\hline IV & $2(1.5 \%)$ & $12(8.9 \%)$ & & $1(1 \%)$ & $6(6 \%)$ & \\
\hline NYHA (III/IV) & 120 (87\%) & $85(62 \%)$ & $<0.001$ & $84(84 \%)$ & 75 (75\%) & 0.15 \\
\hline \multicolumn{7}{|l|}{ Investigations: } \\
\hline Creatinine (mg/dl) & $1(0.8-1.2)$ & $0.9(0.8-1.2)$ & 0.38 & $1(0.8-1.1)$ & $0.9(0.8-1.19)$ & 0.89 \\
\hline Bilirubin (mg/dl) & $0.6(0.4-0.7)$ & $0.6(0.4-0.9)$ & 0.28 & $0.6(0.4-0.9)$ & $0.7(0.4-0.9)$ & 0.12 \\
\hline $\mathrm{EF}$ & & & $>0.99$ & & & $>0.99$ \\
\hline Good (> 50\%) & $100(73.5 \%)$ & 99 (73.9\%) & & $73(73 \%)$ & $74(74 \%)$ & \\
\hline Fair (30-50\%) & $35(25.7 \%)$ & $34(25.4 \%)$ & & $24(24 \%)$ & $23(23 \%)$ & \\
\hline Poor (<30\%) & $1(0.7 \%)$ & $1(0.8 \%)$ & & $1(1 \%)$ & $1(1 \%)$ & \\
\hline IV nitrates & $2(1.5 \%)$ & $1(0.8 \%)$ & $>0.99$ & $1(1 \%)$ & $1(1 \%)$ & $>0.99$ \\
\hline
\end{tabular}

Continuous data were presented as mean \pm SD or median (25th-75th percentiles) and categorical data as numbers and percentages $B M I$ body mass index, BSA body surface area, CVD cerebrovascular disease, DM diabetes mellitus, EF ejection fraction, $H F$ heart failure, $I V$ intravenous, NYHA New York Heart Association, PVD peripheral vascular disease

Patch reconstruction of the LAD can be used in other conditions. Demir and associates performed stent endarterectomy of the LAD and patching in 6 patients with multiple overlapping stents; they reported good postoperative angiographic outcomes [21].

This study showed the feasibility of LAD reconstruction with or without endarterectomy. Hospital outcomes are comparable between both approaches and long-term studies to evaluate how these techniques on survival and graft patency are recommended.

\section{Study limitations}

The study has several limitations, including the retrospective design; however, this study design is acceptable to report these infrequently performed procedures. Several other factors could have affected the outcomes and 
Table 2 Operative data

\begin{tabular}{|c|c|c|c|c|c|c|}
\hline & Group $1(n=138)$ & Group $2(n=137)$ & $P$ & Group $1(n=100)$ & Group $2(n=100)$ & $P$ \\
\hline Emergency surgery & $4(2.9 \%)$ & $2(1.5 \%)$ & 0.68 & $1(1 \%)$ & $2(2 \%)$ & $>0.99$ \\
\hline Distal anastomosis & & & 0.62 & & & 0.61 \\
\hline 1 & $5(3.6 \%)$ & $10(7.3 \%)$ & & $5(5 \%)$ & $8(8 \%)$ & \\
\hline 2 & $44(31.9 \%)$ & $37(27 \%)$ & & $28(28 \%)$ & $25(25 \%)$ & \\
\hline 3 & $77(52.2 \%)$ & $74(54 \%)$ & & $53(53 \%)$ & $57(57 \%)$ & \\
\hline 4 & $16(11.6 \%)$ & $14(10.2 \%)$ & & $14(14 \%)$ & $10(10 \%)$ & \\
\hline 5 & $1(0.7 \%)$ & $2(1.5 \%)$ & & 0 & 0 & \\
\hline CPB time (min) & $95.5(78-120)$ & $98(75-115)$ & 0.45 & $93(78-120)$ & $98(70-115)$ & 0.71 \\
\hline Ischemic time (min) & $58(49-75)$ & $57(44-68)$ & 0.15 & $58(50-73)$ & $55.5(43-65)$ & 0.16 \\
\hline Minimum temperature $(\mathrm{C})$ & $32(30-35)$ & $32(30-35)$ & 0.41 & $33(31-35)$ & $32(30-35)$ & 0.12 \\
\hline Minimum pressure $(\mathrm{mmHg})$ & $50(40-55)$ & $50(40-50)$ & 0.9 & $50(40-55)$ & $50(40-50)$ & 0.98 \\
\hline Maximum pressure $(\mathrm{mmHg})$ & $80(80-80)$ & $80(80-82)$ & 0.95 & $80(80-80)$ & $80(80-80)$ & 0.93 \\
\hline Minimum flow (L/min) & $4(3.7-4.3)$ & $4(3.8-4.3)$ & 0.69 & $4(3.7-4.2)$ & $4(3.8-4.3)$ & 0.82 \\
\hline Hemofiltration & $3(2.34 \%)$ & $1(0.8 \%)$ & 0.62 & $2(2 \%)$ & 0 & 0.5 \\
\hline Blood transfusion & $18(14.1 \%)$ & $15(12.6 \%)$ & 0.85 & $14(14 \%)$ & $12(12 \%)$ & $>0.99$ \\
\hline Coming off bypass & & & 0.17 & & & 0.28 \\
\hline No support & $63(48.5 \%)$ & $72(55.8 \%)$ & & $47(50 \%)$ & $54(58.1 \%)$ & \\
\hline Minimal support & $58(44.6 \%)$ & $51(39.5 \%)$ & & $42(44.7 \%)$ & 37 (39.8\%) & \\
\hline High inotropes & 0 & $2(1.6 \%)$ & & 0 & 0 & \\
\hline IABP & $9(6.9 \%)$ & $4(3.1 \%)$ & & $5(5.3 \%)$ & $2(2.2 \%)$ & \\
\hline
\end{tabular}

Continuous data were presented as mean \pm SD or median (25th-75th percentiles) and categorical data as numbers and percentages $C B P$ cardiopulmonary bypass, IABP intra-aortic balloon pump

not measured in our patients. We performed a propensity score matching to adjust for the measured variables; however, patients' assignment could be confounded by indication. Another limitation is the lack of long-term follow-up, which is vital to detect the effect of both techniques on the long-term patency of the grafts, reintervention, and survival. Moreover, we did not perform routine coronary angiography for all patients, and ECG was the main method for diagnosing postoperative ischemia that warranted further investigations.

\section{Conclusion}

The outcomes after reconstructing extensively diseased LAD with endarterectomy or plaque exclusion and

Table 3 Postoperative outcomes

\begin{tabular}{|c|c|c|c|c|c|c|}
\hline & Group $1(n=138)$ & Group $2(n=137)$ & $P$ & Group $1(n=100)$ & Group $2(n=100)$ & $P$ \\
\hline Low COP & $10(7.2 \%)$ & $8(5.8 \%)$ & 0.84 & $6(6 \%)$ & $4(4 \%)$ & 0.73 \\
\hline $\mathrm{AF}$ & $6(4.4 \%)$ & $4(3 \%)$ & 0.75 & $5(5 \%)$ & $3(3 \%)$ & 0.73 \\
\hline Duration of MV (h) & $9(7-15)$ & $9(8-18)$ & 0.94 & $9(7.5-14)$ & $9(7-14)$ & 0.93 \\
\hline Reoperation & $4(2.9 \%)$ & $7(5.1 \%)$ & 0.38 & $3(3 \%)$ & $5(5 \%)$ & 0.73 \\
\hline Blood transfusion & $80(61.1 \%)$ & 94 (72.9\%) & 0.043 & $60(60 \%)$ & $71(71 \%)$ & 0.11 \\
\hline Sternal rewiring & $4(3.1 \%)$ & $4(3.1 \%)$ & $>0.99$ & $4(4 \%)$ & $3(3 \%)$ & $>0.99$ \\
\hline Re-intubation & $4(3.1 \%)$ & $5(3.9 \%)$ & 0.75 & $4(4 \%)$ & $5(5 \%)$ & $>0.99$ \\
\hline Renal failure & $1(0.8)$ & $1(0.8 \%)$ & $>0.99$ & $1(1 \%)$ & 0 & $>0.99$ \\
\hline ICU stay (hour) & $39(24-72)$ & $30(24-48)$ & 0.53 & $24(24-48)$ & $30(24-48)$ & 0.76 \\
\hline Hospital stay (days) & $7(6-10.5)$ & $7(6-10)$ & 0.62 & $7(6-9)$ & $7(6-10)$ & 0.57 \\
\hline Mortality & $6(4.4 \%)$ & $5(3.7 \%)$ & $>0.99$ & $1(1 \%)$ & 0 & $>0.99$ \\
\hline
\end{tabular}

Continuous data were presented as mean \pm SD or median (25th-75th percentiles) and categorical data as numbers and percentages $A F$ atrial fibrillation, COP cardiac output, ICU intensive care unit 
patching are satisfactory and comparable in both approaches. The choice of the technique should be tailored according to the characteristics and extension of the atherosclerotic plaque. A long-term study to evaluate the effect of these techniques on survival and graft patency is recommended.

\section{Abbreviations}

CABG: Coronary artery bypass grafting; CPB: Cardiopulmonary bypass;

ECG: Electrocardiogram; ICU: Intensive care unit; INR: International normalized ratio; LAD: Left anterior descending artery; LCO: Low cardiac output; LIMA: Left internal mammary artery; RIMA: Right internal mammary artery

\section{Acknowledgements}

Not applicable.

\section{Authors' contributions}

E.F. and M.A. participated in getting the conception, data collection, analysis, and manuscripts writing. All authors read and approved the final manuscript.

\section{Funding}

Not applicable.

\section{Availability of data and materials}

Available by the corresponding author upon request

\section{Ethics approval and consent to participate}

Due to the retrospective nature patients, consent for publication was waved.

\section{Consent for publication}

Not applicable.

\section{Competing interests}

The authors declare that they have no competing interests.

Received: 6 January 2021 Accepted: 14 February 2021

Published online: 24 February 2021

\section{References}

1. Lawrie GM, Morris GCJ, Silvers A, Wagner WF, Baron AE, Beltangady SS et al (1982) The influence of residual disease after coronary bypass on the 5-year survival rate of 1274 men with coronary artery disease. Circulation. 66(4): 717-723

2. Rodgers-Fischl PM, Ferraris VA, Makdisi G. Is Internal Mammary to the Anterior Descending Always the Best Option? Ann Thorac Surg. 2020:500034975(20)32093-2. https://doi.org/10.1016/j.athoracsur.2020.09.060. Epub ahead of print. PMID: 33307068

3. Wang J, Gu C, Yu W, Gao M, Yu Y (2015) Short- and long-term patient outcomes from combined coronary endarterectomy and coronary artery bypass grafting: a meta-analysis of 63,730 patients (PRISMA). Medicine (Baltimore). 94(41):e1781

4. Myers PO, Tabata M, Shekar PS, Couper GS, Khalpey Zl, Aranki SF (2012) Extensive endarterectomy and reconstruction of the left anterior descending artery: early and late outcomes. J Thorac Cardiovasc Surg. 143(6):1336-1340

5. Uchimuro T, Fukui T, Mihara W, Takanashi S (2009) Acute thrombosis after endarterectomy of stented left anterior descending artery. Interact Cardiovasc Thorac Surg 8(6):663-665. Available from. https://doi.org/10.151 0/icvts.2008.201194

6. Nishigawa K, Fukui T, Yamazaki M, Takanashi S (2017) Ten-year experience of coronary endarterectomy for the diffusely diseased left anterior descending artery. Ann Thorac Surg. 103(3):710-716

7. Fukui T, Tabata M, Taguri M, Manabe S, Morita S, Takanashi S (2011) Extensive reconstruction of the left anterior descending coronary artery with an internal thoracic artery graft. Ann Thorac Surg. 91(2):445-451

8. Prabhu AD, Thazhkuni IE, Rajendran S, Thamaran RA, Vellachamy KA, Vettath MP (2008) Mammary artery patch reconstruction of left anterior descending coronary artery. Asian Cardiovasc Thorac Ann. 16(4):313-317
9. Shapira N, Lumia FJ, Gottdiener JS, Germon P, Lemole GM (1988) Adjunct endarterectomy of the left anterior descending coronary artery. Ann Thorac Surg. 46(3):289-296

10. Beretta L, Lemma M, Vanelli P, DiMattia D, Bozzi G, Broso P et al (1992) Coronary "open" endarterectomy and reconstruction: short- and long-term results of the revascularization with saphenous vein versus IMA-graft. Eur J cardio-thoracic Surg Off J Eur Assoc Cardio-thoracic Surg. 6(7):382-386 discussion 387

11. Kato Y, Takanashi S, Fukui T, Naruko T, Shibata T, Shimizu Y (2015) Does the complexity of coronary artery disease affect outcomes after complete revascularization with long segmental reconstruction of the left anterior descending artery using the left internal thoracic artery? Interact Cardiovasc Thorac Surg. 21(3):308-314

12. Ramasubrahmanyam G, Panchanatheeswaran K, Varma Kalangi TK, Nagasaina RG (2019) Surgical management of diffusely diseased coronary arteries. Indian J Thorac Cardiovasc Surg. 35(3):453-460

13. Bitan O, Pirundini PA, Leshem E, Consalvi C, McGurk S, King Q et al (2018) Coronary endarterectomy or patch angioplasty for diffuse left anterior descending artery disease. Thorac Cardiovasc Surg. 66(6):491-497

14. Byrne JG, Karavas AN, Gudbjartson T, Leacche M, Rawn JD, Couper GS et al (2004) Left anterior descending coronary endarterectomy: early and late results in 196 consecutive patients. Ann Thorac Surg. 78(3):864-867

15. Katselis C, Samanidis G, Papasotiriou A, Karatasakis G, Nenekidis I, Demerouti E et al (2017) Outcomes after a left anterior descending artery endarterectomy in advanced coronary artery disease. Cardiovasc Revasc Med. 18(5):332-337

16. Domaradzki W, Sanetra K, Krauze J, Kinasz L, Jankowska-Sanetra J, Swiątkiewicz M et al (2015) Coronary endarterectomy in left anterio descending artery combined with coronary artery bypass grafting midterm mortality and morbidity. Kardiochirurgia i Torakochirurgia Pol = Polish J Cardio-Thoracic Surg 12(4):304-308

17. Soylu E, Harling L, Ashrafian H, Casula R, Kokotsakis J, Athanasiou T (2014) Adjunct coronary endarterectomy increases myocardial infarction and early mortality after coronary artery bypass grafting: a meta-analysis. Interact Cardiovasc Thorac Surg. 19(3):462-473

18. Ogus TN, Basaran M, Selimoglu O, Yildirim T, Ogus H, Ozcan H et al (2007) Longterm results of the left anterior descending coronary artery reconstruction with left internal thoracic artery. Ann Thorac Surg. 83(2):496-501

19. Shen J, Xia L, Song K, Wang Y, Yang Y, Ding W et al (2019) Off-pump onlaypatch grafting using the left internal mammary artery for a diffusely diseased left anterior descending artery: in-hospital and mid-term outcomes. Coron Artery Dis. 30(5):354-359

20. Kato Y, Shibata T, Takanashi S, Fukui T, Ito A, Shimizu Y (2012) Results of long segmental reconstruction of left anterior descending artery using left internal thoracic artery. Ann Thorac Surg. 93(4):1195-1200

21. Demir T, Egrenoglu MU, Tanrikulu N, Cizgici AY, Yildirim Kl, Dindar I et al (2015) Surgical revascularization of the left anterior descending artery with multiple failed overlapping stents. J Card Surg. 30(12):877-880

\section{Publisher's Note}

Springer Nature remains neutral with regard to jurisdictional claims in published maps and institutional affiliations.

\section{Submit your manuscript to a SpringerOpen ${ }^{\circ}$ journal and benefit from:}

- Convenient online submission

- Rigorous peer review

- Open access: articles freely available online

- High visibility within the field

- Retaining the copyright to your article

Submit your next manuscript at $\boldsymbol{\nabla}$ springeropen.com 